\title{
Wireless Sensor Based Forest Fire Early Detection with Online Remote Monitoring
}

\author{
Shobana Mahalingam, Meka Sai Deep, Kotha Sai Krishna
}

\begin{abstract}
Since most countries have an extensive forest resources, there are often, if not constantly, fires that erupt in these countries from these causes. The majority of vulnerable areas are found in warm climates. Since its highest elevation is a hundred and theta, this piece of infrastructure enables substantial vegetation, but since summers are hot and arid, the risks an overload. When global warming gets more intense, these types of disasters will become more frequent and worse. Much more land in the seasonal forest fires have been lost each year due to a destructive cutting practises, the old forestry, as well as assets, such as private residences and other structures. Additionally, it puts firefighters and the general public at risk, who on an equal scale suffer from a lot of death and illness each year.this sensor, microprocessor, and network technology] developed greatly expanded our] so we are now able to reliably detect the current spread of forest fires and begin to respond quickly to their progression.After natural timberland fires are set, which are frequent in remote regions where trees have not been selectively logged, they burn down into tinder, then new trees grow from seeds in their ashes, the older ones' fuel die and that spread. These pieces are particularly susceptible to being set on fire, which is an excellent location for matches and pyrotechnics. Although many a midsummer's day can cause a flame to erupt, the wick to expand, it can also be stoked by the normal process of human activities like smoking or using a heat source. Start running the process just as soon as the components are ready to go up in the flame. As the breeze expands the flame, the basic element of the vapour gets built up.

Keywords: Arduino, IoT, Node MCU, Forest Fire
\end{abstract}

\section{INTRODUCTION}

This project introduces a new type of forest fire early warning systems which utilises a sensor network, called a sensor network, to capture information about potentially fireprone sections and smoking areas and send the information to the centre to the control room about them. the introduction of wireless sensors a wireless sensor network, where a

Manuscript received on May 21, 2021.

Revised Manuscript received on May 26, 2021.

Manuscript published on June 30, 2021.

* Correspondence Author

Shobana Mahalingam, Assistant Professor, Department of Computer Science and Engineering, SRM Institute of Science and Technology,Kattankulathur(Tamil Nadu), India.Email: shobanam@srmist.edu.in

Meka Sai Deep, B.Tech Student, Department of Computer Science and Engineering, SRM Institute of Science and Technology, Kattankulathur(Tamil Nadu), India. Email:mm7256@srmist.edu.in

Kotha Sai Krishna*, B.Tech Student, Department of Computer Science and Engineering,SRM Institute of Science and Technology, Kattankulathur(TamilNadu), India. Email: ks8763@srmist.edu.in

(C) The Authors. Published by Blue Eyes Intelligence Engineering and Sciences Publication (BEIESP). This is an open access article under the CC BY-NCND license (http://creativecommons.org/licenses/by-nc-nd/4.0/) number of low-cost micro sensors are placed in the region or which has a connection to a centralised monitoring facility, with the aid of a communications networks is put into place, monitoring power which is installed nearby Through the use of this system, the Forest Service can pinpoint which fire is on the map, where in the world and keep tabs on fire spread data instantly by using the internet.

\section{PROPOSED METHOD}

This project proposes a system for tracking and alarming for the protection of trees against forest fires. Arduino platform based IOT enabled fire detector and monitoring system is the solution to this problem. In this project we have built fire detector using Arduino UNO which is interfaced with a temperature sensor, a Flame Sensor, a buzzer and Wi-Fi Module. In order to implement this project, we are interfacing 4 Flame Sensor. This Sensor can be placed at 4 Zone of Forest. If any Flame is detected using this Fire Sensor, then it sends signal to Arduino Microcontroller. Arduino Processes this data and display the Zone Name on LCD Module and a High Alert Buzzer Sound is produced. Temperature sensor and Humidity Sensor is used to monitor the real-time temperature and Humidity of Forest Area. This system is interfaced with a Wireless High alert buzzer sound using RF Technology.This System is also interfaced with Remote Online Monitoring System. Arduino Sends data to Node MCU Wi-Fi Module. This Module sends the data to Blynk Application., using this application Forest department can wirelessly monitor the forest condition from anywhere in the world.To Power this entire System we have $12 \mathrm{~V}$ Transformer based Power Supply. 1N4007 diode based full wave rectifier circuit is used rectify $12 \mathrm{~V}$ AC voltage to $12 \mathrm{~V}$ Dc Voltage. Voltage Regulator 7805 and 7812 are used to produce constant $5 \mathrm{~V}$ and $12 \mathrm{~V}$ DC Output. These Voltages are used by Arduino Uno, Wi-Fi Module, Sensors and other Minor Circuit. Filter Capacitors are used to produced Constant and filtered DC Voltage.

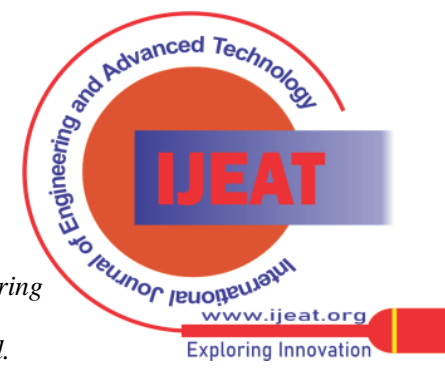




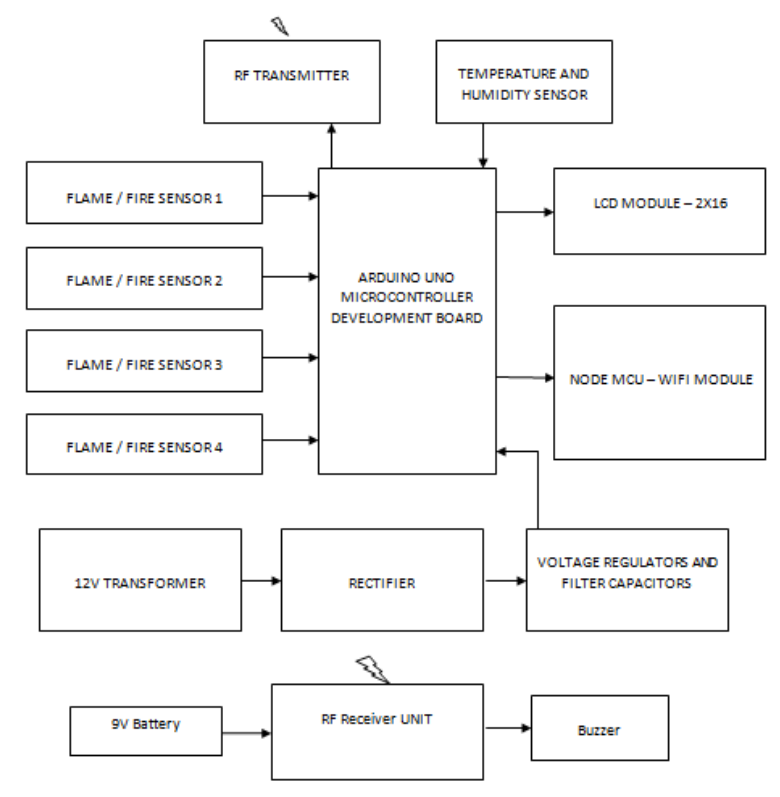

Fig1:Proposed Architecture

- The overall system "Wireless Sensor based Forest Fire early Detection with Online Remote Monitoring" consists of several sensor Modules

○ DHT 11 - Digital Humidity sensor gives moisture value and as well as temperature

- Flames sensor is used to detect any fire in the four Zones of Forest.

- Buzzer module is used to generate sound alert on detecting fire.

- This whole sensor values uploaded to the open source cloud Blynk Server. In that cloud we can visualize the values in form of plots - live updated values

- RF Based system is used for wireless alert for Forest Department

- Arduino is used to process the entire data and display it in LCD Module

- Node MCU is used for Internet connectivity and uploads on Blynk server.

\section{COMPARATIVE STUDY}

For existing, earlier versions of the Forest FireLook microcontroller, Atmegachipsetsystems were used to design the fire detection system. The programming of this microcontroller required the purchase of many extra hardware items such as a Development board, a programmer module, so it required a great expansion. a single flame sensor was earlier used to identify the presence of flames in the forest With this sensor, you are unlikely to detect the fires in the forest from a single locations. Aflame sensor was used to notify the GSM Module of any kindling (unintentional overheating of the phone) if found. But only sending up to 100 messages per day with a GSM-based system creates a limitation.

We are proposing a new model in which the development board is an Arduino is used. The programming process is simple because it has a USB programmer built into the chip. Fire sensors were employed in four zones to see if there were any trees. A RF buzzer serves as a useful form of communication to tell forest rangers of any movement in the vicinity. Current temperature and humidity sensors are integrated in the forest growth chamber to monitor the surroundings. Instead of relying on GSM, we have relied on IOT to monitor Sensor Values such as Flame, Temperature, and Humidity using the application BlynkStimulating Powder, we've started using an IOT sensor from scratch. a Buzzeroperated alarm system is implemented in the woods to warn wildlife when a fire breaks out

\section{IMPLEMENTATION AND RESULTS}

The use of the Arduino UNO was employed in the design of a fire alarm system for greater expansion. This restores a person's sense of freedom because he or she no longer has to check the surroundings for threats. devices will be used to conduct the monitoring in conjunction with sensors For critical events, there are Buzz and/are critical alarms that notify the proper authorities. This is also excellent, this system is inexpensive, has excellent energy efficiency, and relies on instruments that have long lifetimes. Works on the following lines are also are well suited for this design: We have the ability to aggregate the receivers to perform multiple tasks on a single receiver node. (a)2 zone-based fire sensor is employed to detect an accident, the location of the ignition of a zone's fire. The Blynk app can be used as a smart home controller and can keep track of sensors via IoT. RF based is the use for forest rangers who can contact Forest Care District personnel via a mobile phone. the engineering study is expected to have yielded new knowledge that is being put into practice

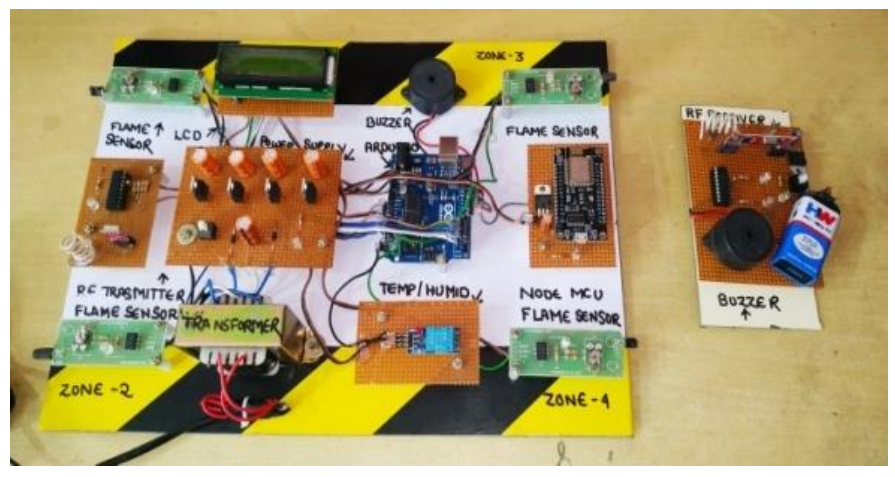

\section{CONCLUSIONS AND FUTURE WORK}

The key to averting/the hallmark of the extraordinary and natural disasters is the early detection of an inferno is the use of caution, as well as the ability to avoid and control any public fire. thus, so therefore, the most important considerations in determining fire conditions include fast and prompt identification and restriction of the source of the flame By building upon the connected devices like the Locus and open source clouds like Blynk, the system will have a realtime picture of forest fires and their locations.

Published By:

Blue Eyes Intelligence Engineering and Sciences Publication

(c) Copyright: All rights reserved.

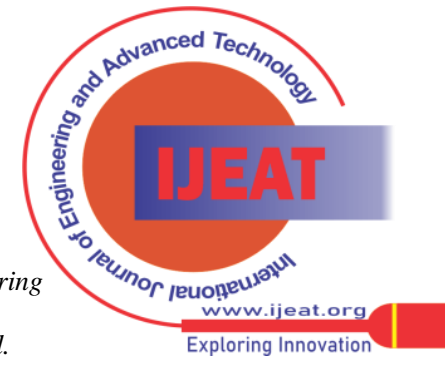


this usage of HTTP Protocol in the ability to transfer the sensor data to the cloud is especially in this way is noteworthy In this project, sensor values are adjusted to either by scenario or Humidity, Temperature, or are sent to the Blynk cloud, while in the cloud are used to maintain the normal values. thus, the system's many attributes can be useful, portable, and economical, and also has the added benefit of making it simple to monitor via the cloud The wireless forest monitoring system, or RF notification system, is employed for public alerts by the agency.

\section{REFERENCES}

1. Stipanicev D., Vuko T., Krstinic D., Stula M., Bodrozic L., “ Forest Fire Protection by Advanced Video Detection System- Croatian Experiences", Split, Croatia, 2006

2. Losso A., Corgnati L., Perona G., “ Early Forest Fire Detection: Smoke Identification through innovative Image Processing using Commercial Sensors", Environment Including Global Change, Palermo, Italy, 2009

3. Kovacs R., Kiss B., Nagy A., Vamos R., "Early Forest Fire De-tection System For Vegetable Fire in the Aggtelek National Park", Budpest, Hungary,2004

4. Kelha V., Rauste Y., Buongiorno A., "Forest Fire Detection by Satellites for Fire Control", European Space Agency, Finland, 2000

5. Manyangadze T., "Forest Fire Detection for Near Real Time Monitoring using Geostationary Satellite", International Institute for Geo-information Science and Earth Observation, Enschede, Netherland, 2009

6. Son B., Her Y., Kim J., "A Design and Implementation of Forest Fire Surveillance System based on Wireless Sensor Network for South Korea", International Journal of Computer Science and Network Security, Vol 6 No. 9B, September 2006

7. Hariyawan M.Y., Gunawan A., Putra E.H., "Wireless Sensor Network for Forest Fire Detection", ISSN:1693-6930,Vol. 11, No. 3, pp. 563 574, September 2013

8. P.J Vivek, G. Raju , S. Akarsh, "Forest Fire Detection System", International Journal of Innovative Research in Science, Engineering and Technology, ISSN: 2319-8753, Vol 3, Issue 6, June 2014

9. Tao H., Zhang H., "Forest Monitoring Application Systems Based on Wireless Sensor Networks", Third International Sym-posium on Intelligent Information Technology Application Workshops, IEEE, 2009

\section{AUTHORS PROFILE}

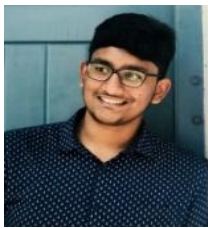

Meka Sai deep, doing degree in B.Tech, Computer Science and Engineering,from SRM Institute of Science and Technology - Kattankulathur2021. His research interests are in Iot, data analytics and web development etc.

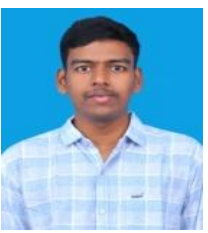

Kothasai Krishna, doing degree in B.Tech, Computer Science and Engineering, from SRM Institute of Science and Technology - Kattankulathur2021. His research interests are in Iot, data analytics and web development, software development etc. apart of academics I received a certificate for database management course through nptel.

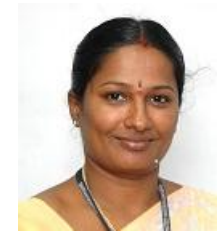

Dr. M. Shobana, received the B.E degree in Electronics and Communication Engineering from Bharathidasan University, Tamilnadu in 2001and M.E(degree) in Computer Science and Engineering (Distinction and rank holder) from Anna university in 2010. Completed her doctorate from Anna University in June 2019.Her research interests are in cloud computing, quantum computing and Networking etc. She has started her career as Lecturer in Santhosha Engineering College in the year 2002.She worked for Santhosha Engineering College for the period of January 2002 to June 2003 and then for Saveetha Engineering College from July 2003 to October 2020.
She is currently working as Assistant Professor in SRM Institute of Science and Technology from November 2020.

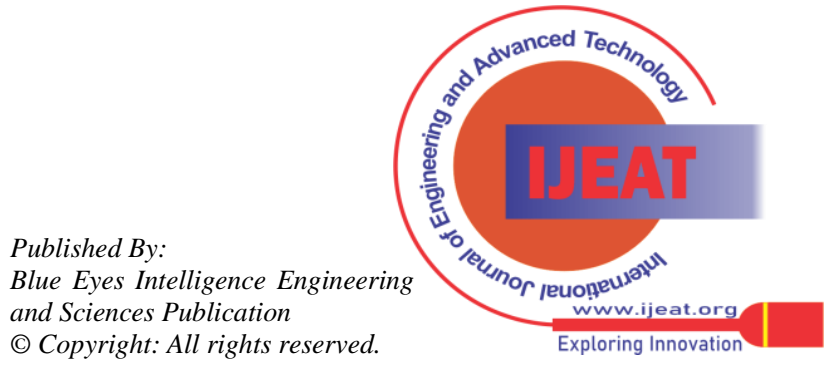

